\title{
A Measuring Method of Gravel's Coefficient of Restitution and Discussion
}

\author{
Yanhui Chen ${ }^{1, *}$, Xinjie Zhang ${ }^{1}$ and Bin Wang ${ }^{1}$ \\ 1. School of Mechanical Engineering, Guangxi University of Science and Technology, 268 East Central \\ Avenue Liuzhou, China
}

\begin{abstract}
In this paper, a simple method for measuring the recovery coefficient of gravel was proposed by the definition of the coefficient of restitution and the principle of kinematics. The recovery coefficient between gravel and slate was obtained by the experiment; meanwhile the reason of error was analyzed and discussed. Finally, the experimental results were compared with the simulation data of the EDEM software. It was concluded that the data were more appropriate when the gravel particles were smaller.
\end{abstract}

\section{Introduction}

The material properties were required to have the material recovery coefficient, which was in many of the simulation software. The coefficient of restitution of the material used in particular was a certain gap found in the book. Meanwhile, the cost of the equipment measured by traditional method was high (measuring the trajectory of the particulate material by the high speed camera). Therefore, this paper provided a simple method of measurement. At the same time, this paper also discussed and analyzed to find the error of this method and the measurement accuracy of the recovery coefficient.

\section{The coefficient of restitution}

The coefficient of restitution refers to the recovery of a physical quantity when two objects collided [1]. Newton first introduced the definition of collision recovery coefficient in the classical mechanics. He defined the ratio of the velocity at which the two objects were about to be separated after the collision and the velocity before the collision would be in order to define the coefficient of restitution $e$.

$$
e=\frac{v_{1}-v_{2}}{v_{10}-v_{20}}
$$

In the Eq. (1), $v_{1}-v_{2}$ as the velocity at which the two objects were about to be separated after the collision; $v_{10}-v_{20}$ as the velocity before the collision.

\footnotetext{
*Corresponding author: gxut_jx@163.com
} 
For the study of the coefficient of restitution, the influence of the collision angle of the recovery coefficient, the experimental method and the significance of the restitution factor were studied in literatures [2-4]. In the literature [5], a new kind of device for measuring the coefficient of restitution was proposed. In this paper, a simple recovery coefficient measuring device was designed by studying the coefficient of restitution and using the principle of kinematics and the definition of the coefficient of restitution in the classical mechanics.

\section{Introduction of experimental device}

Experimental device was shown in Fig.1.

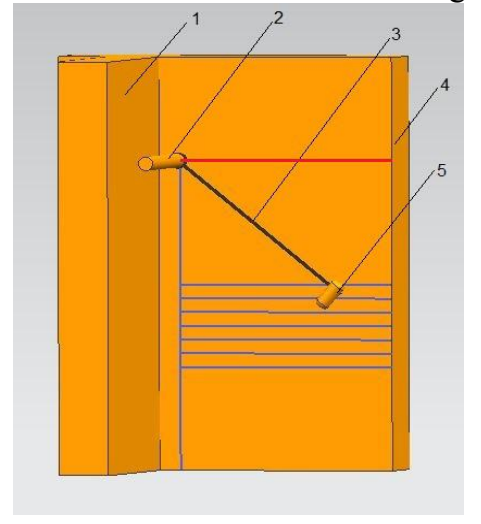

Fig. 1. The experimental device

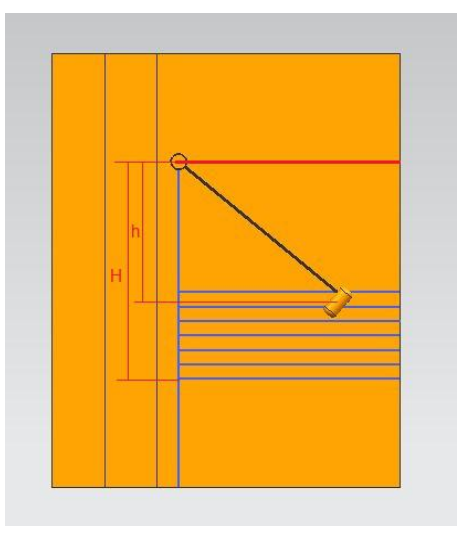

Fig. 2. The experimental principle

In the Fig.1:

1 - the collision plate (can change materials);

2 - the support shaft;

3 - the string (the lower part of it tied to the sample, the upper part of it tight support shaft, the material requirements must be no elasticity);

4 - the scale plate (the lower part of it was the length measuring unit, the maximum range was $35 \mathrm{~cm}$, the horizontal line was the scale line, and the red line was 0 scale line).

5 - the collision sample;

This experimental device measured the recovery coefficient of the material in the form of a positive collision, so it was necessary to ensure that the direction of movement of the sample was perpendicular to the height of the collision plate when the sample collided with the collision plate.

\subsection{Experimental description}

First, the sample was tightened with the string to measure the distance between the support shaft and the center of gravity of the sample at this time. Held the sample and straightened the string and coincided with the 0 scale line. Then released the sample, so that the sample was freed to fall. At this point, the drop height was the distance from the support shaft to the center of gravity of the sample. The sample bounced to a certain height after colliding with the collision plate. At this time there may be various reasons leading to that the rotation of the sample can't be bounced or bounced after the collision to the scale plate, this can' $t$ be successful. Only the trajectory of sample was perpendicular to the plane of collision plate and there was no obvious rotation when the sample bounced, then it was considered successful. Repeated this process several times and recorded this process with the video camera. Later, 
the video processing software be used after slow release, $1 \mathrm{~s}$ can be divided into 25 frames for processing, read the successful bounce height.

\subsection{The principle of experiment}

In the experiment, without considering the mass of the string, the friction loss between the string and the support shaft and between the string and the sample, only gravity work was down in the whole process. Therefore, the velocity of the sample at the collision met the energy conservation.

$$
\frac{1}{2} m v_{10}^{2}=m g H
$$

In the Eq. (2), $m$ is the sample weight, $H$ is the distance from the center of gravity of the sample to the support shaft in the vertical direction, $g$ is the acceleration of gravity and $v_{10}$ is the velocity of the sample before the collision. After the collision, the velocity after the collision can be calculated according to the energy conservation.

$$
\frac{1}{2} m v_{1}^{2}=m g(H-h)
$$

In the Eq. (3), $h$ is the vertical distance from the lowest point after the bounce, $v_{1}$ is the velocity of the sample after the collision.

Because the velocity of the plate has been 0 before and after the collision, so simultaneous Eq. (1) (2) (3) can be obtained Eq. (4).

$$
e=\sqrt{\frac{H-h}{H}}
$$

\subsubsection{Analysis of the device error}

The possible error of the device in measuring the coefficient of restitution of the material was analyzed as follows:

(1) The friction between the string and the support shaft. This friction would consume mechanical energy and transformed it into internal energy, but there was the rolling friction, so bold speculation was less effective and can be ignored.

(2) The friction loss between the string and the sample can be ignored basically, as long as the binding was firm and the displacement was not generated.

(3) A slight rotation was produced even in the case of success, resulting in a lower height of the bounce.

\subsection{Experimental verification}

\subsubsection{The coefficient of restitution of collision between gravel and slate was studied}

In order to verify the feasibility of the experiment device, the coefficient of restitution between the gravel was taken as an example to carry out the experiment. At the same time, 
the parameters be measured which were simulated by EDEM software and compared with the results of the cylinder experiment.

\subsubsection{The coefficient of restitution of the gravel was measured}

In this experiment, three pieces of ordinary gravel of large, middle and small three types were selected as A1, A2, A3, B1, B2, B3, C1, C2, C3 and an ordinary slate as the collision material, which was measured with the experiment device. Among them, the initial height of large, middle and small three kinds of gravel were $32 \mathrm{~cm}, 31.5 \mathrm{~cm}$ and $31 \mathrm{~cm}$ respectively. The size of the gravel was shown in Fig.3.

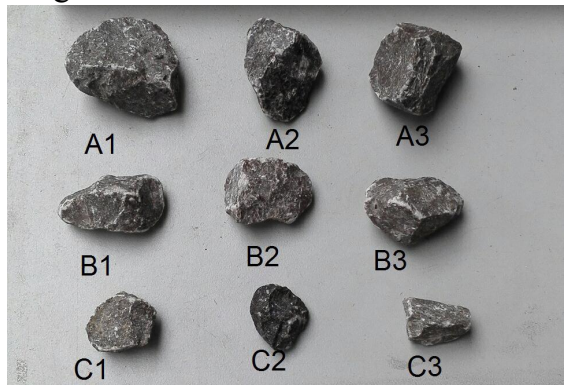

Fig. 3. Gravel size

The measured data were shown in Table 1.

Table 1. Data measured by the device

\begin{tabular}{|c|c|c|c|c|}
\hline Sample & Group & $\begin{array}{c}\text { Initial height } \\
{[\mathrm{cm}]}\end{array}$ & $\begin{array}{c}\text { Bounce height } \\
{[\mathrm{cm}]}\end{array}$ & $\begin{array}{c}\text { Coefficient of } \\
\text { restitution }\end{array}$ \\
\hline & 1 & \multirow{15}{*}{32} & 26.7 & 0.407 \\
\hline & 2 & & 27.3 & 0.383 \\
\hline \multirow[t]{5}{*}{$\mathrm{A} 1$} & 3 & & 26.9 & 0.399 \\
\hline & 4 & & 26.1 & 0.429 \\
\hline & 5 & & 26.3 & 0.422 \\
\hline & 1 & & 27.4 & 0.379 \\
\hline & 2 & & 26.5 & 0.415 \\
\hline \multirow[t]{5}{*}{$\mathrm{A} 2$} & 3 & & 26.3 & 0.422 \\
\hline & 4 & & 26.1 & 0.429 \\
\hline & 5 & & 26.0 & 0.433 \\
\hline & 1 & & 26.5 & 0.415 \\
\hline & 2 & & 25.1 & 0.464 \\
\hline \multirow[t]{5}{*}{ A3 } & 3 & & 27.1 & 0.391 \\
\hline & 4 & & 25.2 & 0.461 \\
\hline & 5 & & 25.5 & 0.451 \\
\hline & 1 & \multirow{12}{*}{31.5} & 26.1 & 0.414 \\
\hline & 2 & & 25.7 & 0.429 \\
\hline \multirow[t]{5}{*}{ B1 } & 3 & & 25.1 & 0.451 \\
\hline & 4 & & 26.8 & 0.386 \\
\hline & 5 & & 25.3 & 0.444 \\
\hline & 1 & & 25.7 & 0.429 \\
\hline & 2 & & 24.3 & 0.478 \\
\hline \multirow[t]{5}{*}{$\mathrm{B} 2$} & 3 & & 24.8 & 0.461 \\
\hline & 4 & & 26.0 & 0.418 \\
\hline & 5 & & 24.1 & 0.485 \\
\hline & 1 & & 24.3 & 0.478 \\
\hline & 2 & & 25.1 & 0.451 \\
\hline
\end{tabular}




\begin{tabular}{|c|c|c|c|c|}
\hline \multirow[t]{5}{*}{ B3 } & 3 & & 26.8 & 0.386 \\
\hline & 4 & & 26.1 & 0.414 \\
\hline & 5 & & 24.7 & 0.465 \\
\hline & 1 & \multirow{15}{*}{31} & 23.0 & 0.508 \\
\hline & 2 & & 21.1 & 0.565 \\
\hline \multirow[t]{5}{*}{$\mathrm{C} 1$} & 3 & & 22.5 & 0.523 \\
\hline & 4 & & 24.2 & 0.468 \\
\hline & 5 & & 23.3 & 0.498 \\
\hline & 1 & & 25.1 & 0.436 \\
\hline & 2 & & 23.9 & 0.478 \\
\hline \multirow[t]{5}{*}{$\mathrm{C} 2$} & 3 & & 25.3 & 0.429 \\
\hline & 4 & & 23.1 & 0.505 \\
\hline & 5 & & 23.3 & 0.498 \\
\hline & 1 & & 23.4 & 0.495 \\
\hline & 2 & & 24.1 & 0.472 \\
\hline \multirow[t]{3}{*}{$\mathrm{C} 3$} & 3 & & 22.8 & 0.514 \\
\hline & 4 & & 21.8 & 0.545 \\
\hline & 5 & & 26.5 & 0.559 \\
\hline
\end{tabular}

Through the experimental analysis of the above data, we can draw the following conclusions: 1. The experimental data had obvious gap for the different gravel, even with the same gravel also had a big difference. As for the reasons, the author thought that on one hand it was the individual difference in the shape and the mass of the different gravel; On the other hand, the same gravel was from different contact point of the collision plate during the collision [6]; 2. For the larger particles of gravel, the values of the recovery coefficient were removed by the obvious large or small values, and the rest values were basically between 0.38 and 0.43 , and the average of this part was 0.41 by calculation; For intermediate particles of gravel, the recovery coefficient was basically concentrated in 0.41 to 0.48 , and the average of this part was 0.447 by calculation; For smaller particles of gravel, the values of the recovery coefficient were removed by the obvious large or small values, and the rest values were basically between 0.46 and 0.55 , the average of this part was 0.50 by calculation; 3 . Different results had been obtained for different sizes of gravel, which fully demonstrated the size of the gravel in this experiment device had a significant impact on the results of the experiment.

\subsubsection{The repose angle was measured by cylinder test}

The bottomless cylinder experiment was one of the many experiment devices for measuring the repose angle. The bottomless cylinder be placed in a horizontal plane with the gravel filled cylinder, and then lifted cylinder slowly and vertically, the gravel was free to fall under the action of the gravity, then a cone formed by natural flow. In this experiment, the cylinder with the aspect ratio of 1.5:1 was used to fill the gravel with randomly, and it was lifted with uniform speed by the hoist. The gravel formed the rest angle on the ground covered by PVC plate, then took a picture perpendicular to the ground and measured the rest angle in the picture.

Measurement of experimental data was shown in Table 2.

Table 2. The rest angle of cylinder test measured

\begin{tabular}{|c|c|c|}
\hline Sample Classification & Rest Angle $\left[{ }^{\circ}{ }^{\circ}\right.$ & Average $\left[{ }^{\circ}\right]$ \\
\hline 1 & 27.6 & \multirow{2}{*}{26.5} \\
\hline 2 & 26.4 & \multirow{2}{*}{} \\
\hline 3 & 26.6 & \\
\hline 4 & 28.1 & \\
\hline 5 & 26.2 & \\
\hline
\end{tabular}




\begin{tabular}{|c|c|}
\hline 6 & 23.9 \\
\hline 7 & 27.8 \\
\hline 8 & 25.6 \\
\hline 9 & 26.8 \\
\hline 10 & 26.1 \\
\hline
\end{tabular}

\subsection{EDEM simulation}

Li et al. [7] showed that it was proved that the parameter calibration in EDEM software can predict the motion of particles correctly by the rest angle experiment under the different devices with the ball made of different materials and compared with the simulation results of EDEM software. The size of the rest angle was calculated by simulating the three coefficient of restitution measured above.

A bottomless cylinder model was established with the radius of the bottom circle being $100 \mathrm{~mm}$, and the height being $500 \mathrm{~mm}$ (the height of the cylinder was raised so as to facilitate the generation of particles), the material was set as PVC. The ground area was set to 1000 $\mathrm{mm} * 1000 \mathrm{~mm}$, and the material was PVC. The shape of gravel was irregular, so two kinds of irregular particles were set up. Its shape was shown in Fig.4, each of the two models consists of four different circular particles, in which the maximum diameter of particle 1 was $18.5 \mathrm{~mm}$, and the maximum diameter of particle 2 was $20.5 \mathrm{~mm}$. When the particles were generated, the gradation measured according to the above tests were divided into four levels of size, which were 1 times, 1.5 times, 2 times and 2.5 times the original particle size respectively. The weight measured under each gradation of experimental gravel was used as the standard for the generation of the individual particle levels, which were $6.36 \mathrm{~kg}, 2.86 \mathrm{~kg}$, $2 \mathrm{~kg}$ and $1.23 \mathrm{~kg}$ respectively. The lifting speed of the cylinder was measured actually by $0.06 \mathrm{~m} / \mathrm{s}$, the cylinder moved in a straight line in the positive direction of the $\mathrm{Z}$ axis after 0.6 $\mathrm{s}$ due to the early stage of particles generation to a steady state needed $0.5 \mathrm{~s}$, until the end of the simulation. The values of the rest angle were obtained by the screenshot measurement. The simulation parameters were shown in Table 3.

Table 3. Simulation parameters

\begin{tabular}{|c|c|c|c|c|c|c|}
\hline \multirow[b]{2}{*}{ Material } & \multicolumn{6}{|c|}{ Parameters } \\
\hline & $\begin{array}{c}\text { Density } \\
{[\mathrm{kg} \cdot \mathrm{m}-3]}\end{array}$ & $\begin{array}{c}\text { Shear } \\
\text { modulus } \\
{[\mathrm{GPa}]}\end{array}$ & $\begin{array}{l}\text { Poisson's } \\
\text { ratio }\end{array}$ & $\begin{array}{c}\text { Sliding } \\
\text { friction } \\
\text { coefficient }\end{array}$ & $\begin{array}{c}\text { Rolling } \\
\text { friction } \\
\text { coefficient }\end{array}$ & $\begin{array}{l}\text { Coefficient } \\
\text { of } \\
\text { restitution }\end{array}$ \\
\hline Gravel & 2090 & 11.1 & 0.29 & & & \\
\hline PVC & 1400 & 1.45 & 0.35 & & & \\
\hline $\begin{array}{l}\text { Gravel and } \\
\text { the } \\
\text { ground(PVC) }\end{array}$ & & & & 0.47 & 0.002 & 0.45 \\
\hline $\begin{array}{l}\text { Gravel and } \\
\text { gravel }\end{array}$ & & & & 0.84 & 0.004 & $\begin{array}{l}\text { A: } 0.41 \\
\text { B: } 0.45 \\
\text { C: } 0.50\end{array}$ \\
\hline $\begin{array}{l}\text { Gravel and } \\
\text { cylinder wall } \\
\text { (PVC) }\end{array}$ & & & & 0.47 & 0.002 & 0.45 \\
\hline
\end{tabular}




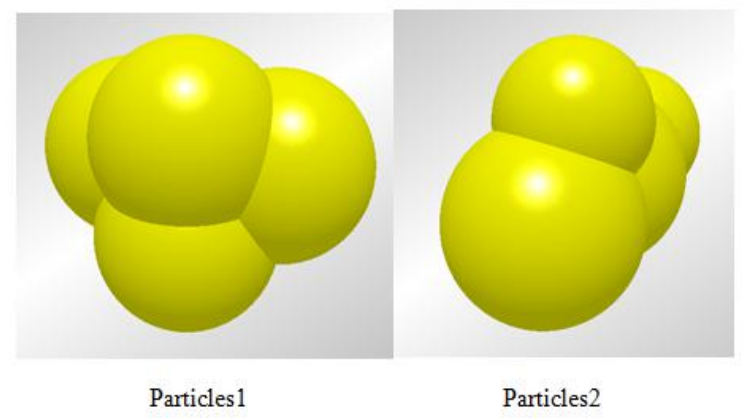

Fig. 4. Particle model

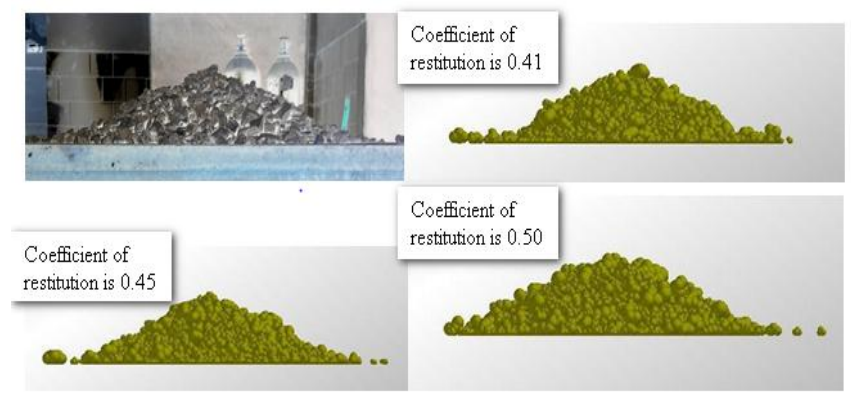

Fig. 5. Image contrast

\subsubsection{The contrast between simulation results and experimental results}

The results obtained by repeated simulation were shown in Table 4. Fig.5 was a comparison of the experiment and the simulation.

Table 4. The results of simulation data

\begin{tabular}{|c|c|c|c|c|c|}
\hline Group & $\begin{array}{c}\text { Rest Angle } \\
{\left[{ }^{\circ}\right]}\end{array}$ & Group & $\begin{array}{c}\text { Rest Angle } \\
{\left[{ }^{\circ}\right]}\end{array}$ & Group & $\begin{array}{c}\text { Rest Angle } \\
{\left[{ }^{\circ}\right]}\end{array}$ \\
\hline A1 & 31.5 & B1 & 26.5 & C1 & 25.6 \\
\hline A2 & 30.2 & B2 & 28.2 & C2 & 26.0 \\
\hline A3 & 28.8 & B3 & 26.2 & C3 & 27.2 \\
\hline A4 & 32.2 & B4 & 30.4 & C4 & 28.3 \\
\hline
\end{tabular}

In the Table 4, The recovery coefficient of the large particles in Group A was bigger than the simulation results, and the error was larger with the experimental results. The experimental results of Group B and Group C were smaller error compared with Group A. It can be seen from Fig.5, the Group B and C were more similar to the experiment, but the simulation data of Group $C$ were basically consistent with the experimental data, and the part values of the Group B were too large, therefore the recovery coefficient of the Group C were more appropriate.

\section{Conclusions}

Through the comparison, we found that the recovery coefficient of the small particle was the most suitable as the simulation parameters. The large particle measured values smaller, the 
author thought that the larger the gravel was, the greater its mass was, and the greater the tension on the string, resulting in the greater friction loss between string and support shaft, and the greater friction loss between string and the large particle of gravel, resulting in a smaller measurement result eventually. And, the smaller particles had little effect because of lighter.

The method proposed in this paper can accurately and conveniently measure the coefficient of restitution of collision between the materials. The comparison experiment shown that when the smaller particles were chosen, the experiment results were closest to the theoretical data and the simulation results were more accurate.

This work is supported by Guangxi Science and Technology Development Program Funded Projects: The construction of the comprehensive test platform about earthmoving machinery operation process (No. GuiKe 1598021-2).

\section{References}

1. C. L. Wang. The discussion of the coefficient of restitution. University Physics, 16, 3(1997)

2. Y. Wang. The discussion of the one-dimensional head-on collision coefficient of restitution. The Physical and Engineering, 24, 4(2014)

3. S. M. He, Y. Wu, and X. P. Li. Rolling impact study coefficient of restitution. Rock and Soil Mechanics, 30, 5(2009)

4. C. H. Xu. The meaning and scope of coefficient of restitution. Physical Bulletin, 4, 2(1998)

5. M. J. Yang, L. Yang, and Q. D. Li. Simple granular material coefficient of restitution measurement method and its application. Agricultural Mechanization Research, 10, 3(2009)

6. Z. Y. Qin and Q. S. Lu. Based on the coefficient of restitution of collision simulation. J. Dynamics \& Control, 4, 5(2006)

7. Y. J. Li and Y. Xu. Colin Thornton. A comparison of discrete element simulations and experiments for 'sandpiles' composed of spherical particles. Powder Technol., 160, $10(2005)$ 